\title{
Political blogs and representative democracy
}

\author{
Stephen Coleman ${ }^{\mathrm{a}}$ and Scott Wright ${ }^{\mathrm{b}}$

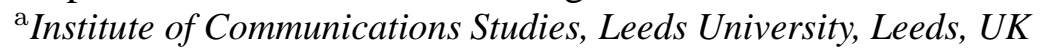 \\ ${ }^{\mathrm{b}}$ School of Political, Social and International Studies, University of East Anglia, Norwich, UK
}

Representative democracy faces profound problems. Electoral turnout has declined to such an extent that the legitimacy of the mandate to govern is drawn into question [19,p. 33]. This problem is exacerbated and reinforced by a feeling of disconnection and distrust between the governed and the governors and a perception that voting and other forms of participation do not influence electoral outcomes or policymaking. At the heart of this 'crisis', as it is sometimes referred to, is an increasingly disrupted and distorted process of political communication. Without effective communication flows, representation cannot be democratic. Responding to this situation calls for a normative account of what effective representative democracy entails [2]. One way of conceiving the desired paths for democratic political communication is in terms of cultural, spatial and temporal distance. The more political communication is characterised by the appearance and reality of such distances, the more likely it is to frustrate claims by political representatives to speak for the public - leaving citizens feeling like remote spectators upon the spectacle of political of representation. Conversely, there are normative and practical benefits to be derived from forms of political communication which engender various dimensions of closeness between representatives and represented.

The perceived pre-eminence of mass-mediated forms of political communication, both ideally and practically, has led authors such as McNair [16, p. 5] to exclude direct communication between political organizations and citizens from diagrams of mediated political communication. The weakening of direct - and, specifically, interactive - communication, between citizens and elected representatives is an important aspect in the perceived crisis of political communication. As governments have come to believe that the public don't know how to speak and the public has come to believe that governments don't know how to listen [4], a wall of suspicion and incomprehension seems to separate the politically represented from their elected representatives. For many critics, the mass media are key accomplices in this process, seemingly 'dumbing down' political coverage by forgoing substance in favour of spin $[6,9$, $12,13,18]$. As Jamie Oliver contended with school dinners, media content is cheap, popular and quick but devoid of 'goodness'; we need some substance to our media sustenance [8].

The need for a renewed relationship between citizens and politicians is addressed by the latest in vogue information and communication technology, the Weblog, or blog. Not since the dot com boom has the democratising potential of a technological tool been the focus of so much attention. A blog is a regularly updated webpage (often described as an online diary), with information (textual, photographic or video) presented in reverse chronological order. According to Ferguson and Griffiths [7, p. 366], in political blogs 'the content focuses on issues, events and policy in a constituency, national, international or party political context.' Political blogs can be individualised (for example personal blogs by MPs, citizens or journalists) or multiple author groups (for example Greenpeace). Blogs provide four principal avenues for enhancing political communication: 
- they reduce the degree of distance between message producer and message receiver, resulting in what often seems like an unmediated mode of communication;

- they enhance interactive dialogue by enabling message receivers to respond directly to blog content;

- they allow message producers to present an appearance of listening to comments from the public and to change their messages accordingly;

- they give rise to new forms of grass-roots, participatory journalism, enabling anyone to set themselves up as a provider of or commentator upon news

These features could potentially increase the accountability and transparency of elected representatives and government in general. Stated optimistically, blogs are thought to be providing new communication channels that can temper or reverse the crisis in political communication by challenging the indirectional flow of message traffic that has tended to characterise mass-mediated democracy. The following triadic diagram of political communication succinctly highlights this claimed potential, and is the starting point for understanding the linkages between the different studies presented in this special issue:

Triangulated Diagram of Political Communication

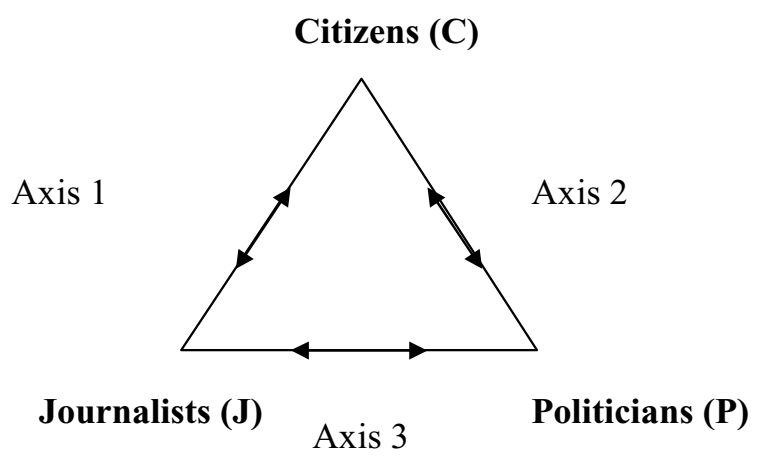

Firstly, blogs have the potential to strengthen C-P communication along Axis 2 - bypassing the mediated route of axes 1-3. The communication along Axis 2 could be both one way $(C \rightarrow P$ or $P \rightarrow C)$, or interactive $(\mathrm{C} \Leftrightarrow \mathrm{P})$. In their article, Stephen Coleman and Giles Moss urge a note of caution when attempting to understand the processes and strategies that are used in constructing such communicative relationships. Analysing the blogs of three prominent politicians (Margot Wallström, David Cameron and David Miliband) through Scannell's 'for-someone-as-everyone' theoretical frame, they show how politicians have attempted to construct a perception of closeness with citizens by adopting symbolic indicators of their ordinariness; by appearing to communicate spontaneously and simultaneously; and by offering the possibility of interactive dialogue. Broader empirical analysis of the blogging practices of elected representatives, and the forms of communication facilitated, are provided by Mary Francoli and Steve Ward, Scott Wright, and Nigel Jackson.

Francoli and Ward comparatively analysed all the blogs of MPs in the UK and Canada, finding that blogging has grown, and continues to grow in the UK, but has dwindled in Canada. The differences are linked to divergent political and institutional environments. No consistent style of blogging was noticeable, though the most successful tended to be driven either by established 'characters', such as the MP Boris Johnson, or were focused on the 'inside' world of party campaigns and political anoraks. Though a small minority used their blog as a tool for hearing citizens' opinions and engaging in debate, 
the majority were actually akin to the traditional soapbox style of broadcast monologue: the ' $\mathrm{P}$ ' generally communicated to rather than with the ' $\mathrm{C}$ '.

Scott Wright has analysed the blogs of councillors using the central government-funded Read My Day civic leadership blogging platform, finding that they were used as tools of representation rather than election campaigning. Similar to Francoli and Ward, a mixed picture is uncovered. Some councillors do use their blogs to broadcast $(\mathrm{P} \rightarrow \mathrm{C}$ ) more personal, direct and detailed information, which could help strengthen their relationship with citizens. However, there is evidence that political parties are attempting to influence the blog content of councillors. Examples of councillors seeking comments from, listening to and interacting with members of the public was limited though; indeed, councillors often did not reply to comments. This is compounded by a general lack of engagement with the broader blogosphere, leading to a danger that politicians and the politically active will end up talking amongst themselves, detached and insulated from broader societal discussions online.

Wright's finding that councillors used blogs as tools of representation is not mirrored in Nigel Jackson's analysis of MPs blogs. Conducted over a 3 month period in early 2005 (shortly before the General Election was called), Jackson's empirical analysis found that MPs did not generally use their blog to promote the party or scrutinize government. Rather, MPs often blogged to a national or issue-based e-constituency, beyond their immediate local arena: a 'rifle' rather than 'scattergun' approach to political communication was adopted. Supported by interviews, Jackson goes on to argue that this was informed by a Burkean conception of democratic representation. On occasion, some of the MPs (3) did seek the opinions of their readers and engaged in debates $(C \Leftrightarrow P)$. Moreover, interview evidence suggested that some were influenced by the debates, such as by helping to inform the asking of a Parliamentary Question. Compared with the later study of MPs blogs provided by Francoli and Ward, it would appear that as the number of blogging MPs has grown in the UK, their focus has also diversified somewhat.

Blogs also have the potential to change the nature of journalism and the democratic functions that the fourth estate is assumed to perform in liberal theories of the mass media. Firstly, as print and broadcast journalists adopt their own blogs, this can help to 'democratise' news production processes, bringing citizens closer [10,15]. The Mums' Army blog, analysed by Tracy Simmons, provides an interesting and unusual example of this. Grounded in Plummer's model of intimate citizenship, Simmons argues that the Mums' Army blog is illustrative of how personal and intimate narratives are increasingly used in political discourses. The success of the blog, indicated by the volume of stories and the messages contained therein, shows that blogs can be used to promote and organise both on and off line social and political activity (including putting forward local election candidates) in the perceived absence of effective action/representation from more traditional bodies such as politicians and police. Secondly, there are a burgeoning number of bloggers who attempt to operate as journalists - reporting on politics with a mixture of news, commentary and investigative journalism. This "grassroots journalism" may produce different kinds of story and new pressures for transparency and accountability - both for politicians and the media - narrowing (or blurring) the gaps along each axis of the triangular model. Thirdly, as found by both Wright and Francoli and Ward, the print and broadcast media often play a crucial promotional role for blogs. The downside is that media scrutiny of blog content has also led to adverse, critical publicity and thus there is a constant play off and considerable self-censorship.

A further contribution of political blogs to democratic reinvigoration relates to the state of the public sphere. By lowering points of entry to public debate, there is a sense in which the blogosphere can be seen as an embryonic space in which 'something approaching public opinion can be formed' [11, p. 49]. Eugenia Siapera's article in this issue considers the scope for subjective representation in the blogosphere. She argues that the 'subjective, idiosyncratic, exclusionary and non-deliberative aspects 
of blogs preclude their function as a public sphere', but that the 'democratic promise of the blog might therefore be located in its potential to deliver an autonomous yet connected subject, and through this to found a new politics revolving around autonomy as the ability of subjects/communities to institute consciously and on their own the rules for their political functioning.' This emphasis upon autonomy raises interesting questions about the role of the individual subject within public politics. Axel Bruns, on the other hand, takes a sanguine view of blogs as countering the mass-mediated public sphere in which accurate representations of public opinion are rare. His article discusses what he describes as 'a communal process of gatewatching in which bloggers and citizen journalists identify and link to or directly cite relevant materials as they become available.' Like Siapera, he does not see this as contributing to a singular, Habermasian public sphere, but to a series of overlapping spheres initiated by issue publics.

All of the analyses offered in this special issue attempt to make sense of the hype surrounding political blogs and uncover how they are being used in practice. Previous claims that new information and communication technologies will revolutionise democratic systems [17, p. 160] have been challenged by empirical research: a range of institutional and social factors shape new technologies' revolutionary potential into an evolutionary reality $[1,3,5,14,20-23$, p. 170]. We must be careful, however, not to dismiss the democratising potential of blogs, even if their effects are not found to be revolutionary; incremental or 'limited' changes are themselves of potential importance. (Wright, this volume) In other words, if the effect is one of reinforcement, its democratic value must still be carefully considered. Thus articles in this special issue analyse how blogging is, or is not, influencing traditional practices of representation, governance and electoral campaigning, as well as more innovative political activities. Specifically, the articles which follow ask:

1. Why politicians and other bodies choose to blog, and the structural, personal and political factors that influence and shape this.

2. The rhetorical and technical devices employed to create a semblance of intimacy between representatives and represented (while maintaining the governing at a distance nexus).

3. The content and interactivity (or not) of Blogs.

4. The audiences for blogs, and whether they extend beyond the already active minority.

5. The extent to which Blogs alter political subjectivities, and the mobilization of these subjectivities, in the context of self-authorship and Web 2.0.

6. How blogs are shaping new forms of journalism and accountability.

It has not been our intention to answer these questions with a view to arriving at a conclusive editorial position. The political blogosphere is too young for there to be anything resembling a definitive judgement. But we are convinced that the emergence of political blogs is indicative of a changing political communication environment. Three characteristics are indicative of this period of change. Firstly, a movement away from the industrial model of political message dissemination towards one in which messages emerge through distributed production. Whether or not one accepts the somewhat teleological claims for Web 2.0 as a new era in which the Internet is returning to its original purpose, there is no doubt that the rise of social networking shifts the locus of political communication further than ever before from the broadcast model. Bruns's notion of 'produsage' is particularly helpful in explaining the open, dispersed, permanently unfinished character of opinion formation which is a consequence of lowered entry barriers to the process of producing and commenting upon public knowledge. The empirical question is whether these new sources of knowledge can compete effectively with centralised, well-resourced industrial-style policy-making machines, such as political parties and governments. 
A second characteristic of the new political communication environment is an erosion of hitherto wellguarded boundaries between rational-institutionalist and affective-personal styles of communication. Politicians are eager to translate impersonal policies into the vernacular language of the lifeworld. Blogs provide an ideal strategic opportunity to present governmental logic as emanating from everyday culture. Coleman and Moss (this issue) cast doubt upon these attempts to subjectivise rationalities of statehood, but the attempt to do so is clearly indicative of a new stage in democratisation in which cultural credibility is regarded as being no less significant than economic delivery.

Thirdly, blogs raise new questions for what used to be called audience research - a term which has only to be introduced in this context to illustrate the complexities of thinking about the direct and indirect reception of these political messages. We know very little about who reads political blogs and who within that relatively small minority actively interacts with them. Are political bloggers talking to themselves, each other, the already converted or at least some people who would otherwise not be reached through the usual channels? The articles in this special issue do not provide answers to that question, but do raise some challenging thoughts about what political communication might mean in the absence of a mass audience or public. Future research into the reception of blogs, both directly and via other media, will explain a great deal about the sustainability of this genre as an instrumental strategy rather than an expressive novelty.

\section{References}

[1] C. Bellamy and J. Taylor, Governing in the Information Age, Open University Press, Buckingham, 1998.

[2] H. Catt, Democracy in Practice, Routledge, London, 1999.

[3] S. Coleman, Blogs and the New Politics of Listening, Political Quarterly 76(2) (2005a), 272-280.

[4] S. Coleman, Direct Representation: Towards a Conversational Democracy, IPPR, London, $2005 \mathrm{~b}$.

[5] S. Coleman, E-Democracy: the History and Future of an Idea, in: The Oxford Handbook of Information and Communication Technologies, R. Mansell, C. Avgerou, D. Quah and R. Silverstone, eds, Oxford University Press, Oxford, 2006, pp. 362-382.

[6] A. Davis, Public relations, news production and changing patterns of source access in the British national media, Media, Culture \& Society 22(1) (2000), 39-59.

[7] R. Ferguson and B. Griffiths, Thin Democracy? Parliamentarians, Citizens and the Influence of Blogging on Political Engagement, Parliamentary Affairs 59(2) (2006), 366-374.

[8] B. Franklin, Packaging Politics: Political Communications in Britain's Media Democracy, Edward Arnold, London, 1994.

[9] I. Gaber, Government by spin: an analysis of the process, Contemporary Politics 5(3) (1998), 263-276.

[10] D. Gillmor, We The Media: grassroots journalism by the people for the people O'Reilly, Sebastopol, CA, 2004.

[11] J. Habermas, The public sphere: An encyclopedia article, New German Critique 3 (1974), 49-55. Available at: http://www.jstor.org/view/0094033x/ap020005/02a00050/0.

[12] N. Jones, Soundbites and Spin Doctors, Cassell, London, 1995.

[13] N. Jones, Sultans of Spin, Victor Gollancz, London, 1999.

[14] M. Margolis and D. Resnick, Politics as Usual: The "Cyberspace Revolution”, Sage Publications, Thousand Oaks, CA, 2000.

[15] D. Matheson, Weblogs and the epistemology of the news: some trends in online journalism, New Media \& Society 6(4) (2004), 443-468.

[16] B. McNair, An Introduction to Political Communication, Routledge, London, 1995.

[17] J. Naisbitt, Megatrends, Pan, London, 1991.

[18] B. Pfetsch, Government news management - strategic communication in comparative perspective, Berlin, WZB, 1999.

[19] Power Inquiry, Power to the People, The Report of Power: An Independent Inquiry into Britain's Democracy, York Publishing, York, 2006.

[20] B. Winston, Media, Technology and Society: a history from the telegraph to the internet, Routledge, London, 1998.

[21] S. Wright, Design Matters: the political efficacy of government-run online discussion forums, in: The Internet and Politics: citizens, voters, and activists, S. Oates, D. Owen and R. Gibson, eds, Routledge, London, 2005, pp. 80-99. 
[22] S. Wright, Electrifying Democracy: Ten years of policy and practice, Parliamentary Affairs 59(2) (2006a), 236-249 (Special Issue: Politics and the Net: the first ten years).

[23] S. Wright, Government-run Online Discussion Fora: moderation, censorship and the shadow of control, British Journal of Politics and International Relations 8(4) (2006b), 550-568. 